\title{
МЕТОДИЧЕСКИЕ ОСНОВЫ ПОДГОТОВКИ СВЯЗУЮЩИХ В ВОЛЕЙБОЛЕ ГЛУХИХ
}

\section{METHODOLOGICAL FOUNDATIONS OF TRAINING OF SETTERS IN VOLLEYBALL FOR THE DEAF}

\section{Schneider}

Summary: The purpose of the study presented in this article was to search for the optimization of the training process in terms of improving the tactical skill of setters in deaf volleyball, which have the most significant effect on sports results. A training module for tactical training of deaf setters developed using a reference model of tactical actions, in the form of a phased formation of skills for choosing a solution based on taking into account typical game situations, and its effectiveness experimentally proved.

Keywords: volleyball for the deaf, training of setters, training methodology, sports confrontation, decision tree.

\author{
Шнейдер Виктор Юдович \\ доцент, заслуженный тренер России, Сургутский \\ государственный университет, г. Сургут \\ shv.53@mail.ru
}

Аннотация: Целью исследования, представленного в статье, явился поиск оптимизации тренировочного процесса в части совершенствования тактического мастерства связующих игроков в волейболе глухих, оказывающего наиболее существенное влияние на спортивный результат. Разработан тренировочный модуль тактической подготовки связующих игроков команды глухих волейболистов с использованием опорной модели тактических действий, в виде поэтапного формирования навыков выбора решения на основе учета типичных игровых ситуаций и экспериментально доказана его эффективность.

Ключевые слова: волейбол глухих, подготовка связующих игроков, методика тренировки, спортивное противоборство, дерево решений.

тельная деятельность глухих волейболистов.

Предмет исследования - методика подготовки связующих в волейболе глухих.

Цель исследования - выявить компоненты тренировочного процесса в части совершенствования тактического мастерства связующих игроков в волейболе глухих, оказывающие наиболее существенное влияние на спортивный результат, разработать тренировочный модуль тактической подготовки связующих игроков команды г. Сургута, с использованием поэтапного формирования навыков выбора решения на основе учета типичных игровых ситуаций и экспериментально проверить его эффективность.

В ходе исследования решались задачи:

1. Сформулировать методические основания при выборе решения связующим игроком с целью повышения эффективности учебно-тренировочной и соревновательной деятельности в волейболе глухих.

2. Провести анализ игры связующих игроков в команде глухих и слабослышащих волейболистов г. Сургута, и оценить эффективность их тактических действий.

3. Разработать тренировочный модуль тактической подготовки связующих игроков с использованием поэтапного формирования навыков выбора решения на основе учета типичных игровых ситу- 
аций.

4. Экспериментально проверить эффективность тренировочного модуля тактической подготовки связующих игроков команды глухих и слабослышащих волейболистов г. Сургута, с использованием поэтапного формирования навыков выбора решения на основе учета типичных игровых ситуаций.

Гипотеза исследования - предполагается, что исследование позволит разработать тренировочный модуль тактической подготовки связующих игроков команды глухих и слабослышащих волейболистов г. Сургута, с использованием опорной модели тактических действий, в виде поэтапного формирования навыков выбора решения на основе учета типичных игровых ситуаций и экспериментально доказать его эффективность.

Новизна - разработан тренировочный модуль тактической подготовки связующих игроков команды г. Сургута, с использованием опорной модели тактических действий «дерево решений», в виде поэтапного формирования навыков выбора решения на основе учета типичных игровых ситуаций в волейболе глухих и слабослышащих.

Теоретическая значимость исследования: обоснована эффективность методики подготовки связующих игроков в волейболе глухих с использованием опорной модели тактических действий, в виде поэтапного формирования навыков выбора решения на основе учета типичных игровых ситуаций.

Практическая значимость работы: разработаны научно обоснованные практические рекомендации по оптимизации учебно-тренировочного процесса в волейболе глухих.

Создание теории игрового противоборства в волейболе в значительной степени повлияло на развитие методики тренировки $[6,12,14]$.

В действиях игроков на волейбольной площадке отражены все стороны спортивной подготовки, все компоненты соревновательной и тренировочной деятельности представляют систему взаимовлияющих подсистем, которую можно представить в виде иерархии ступеней подготовки с системообразующими элементами и своими закономерностями.

Первая ступень - от уровня физических способностей зависит эффективность любого двигательного действия.

Вторая ступень - физические способности предоставляют возможность достигать эффективности в игре через технику.

Третья степень - высокий результат технических приемов достигается через тактические действия.

Связь видов подготовки предполагает сложное взаимодействие факторов, определяющих эффективность, как действий отдельных игроков, так и команды в целом на основе согласованности компонентов соревновательной деятельности [13].

Формирование связей между всеми видами подготовки естественно включается в задачи интегральной подготовки. По определению Ю.Д. Железняка «соревнования являются высшей формой интегральной подготовки» [3]. В тренировочном процессе создать специфические соревновательные условия в полной мере нельзя, так как двусторонние учебные игры лишь частично решают данную проблему. Соревновательная подготовка в обязательном порядке хорошо продумывается, планируется и реализуется в многолетней подготовке волейболистов.

От наличия обратных связей в спортивных состязаниях в значительной степени зависит, будет ли эффективным тренировочный процесс, а, следовательно, и конечный спортивный результат. Насущная потребность в получении информации о структуре, течении и исходе соревновательной деятельности привело к разработке спортивными специалистами различных систем записи игровых действий. Спектр таких систем записи и анализа постоянно расширялся, громоздкие и неэффективные отсеивались, наиболее удачные получали путевку в жизнь, и с успехом использовались на соревнованиях и для оптимизации тренировочного процесса. Необходимо заметить, что вся игровая деятельность волейболистов достаточно хорошо поддается формализации, т.е. описанию соревновательного противоборства языком математики.

Как было выше сказано, в процессе анализа игровой деятельности волейболистов и развития научно-методического сопровождения было создано большое количество систем записи и оценки эффективности игровых действий, из которых до наших дней дошли две, и то, они используются в основном любительскими командами. Принцип записи и последующий анализ игровых действий, предложенный М.Е. Амалиным, прочно утвердился в отечественной науке и практике волейбола [5].

Анализ игр мировых и европейских чемпионатов по волейболу показал высокую степень корреляционных связей между результативностью на подаче, в нападении, блоке и конечным результатом игр [12].

К настоящему времени в теории и практике волейбо- 
ла принят термин «связующий игрок», основная игровая функция которого - поддерживать и осуществлять связь между защитой и нападением. Этот факт подчеркивает важность функции связующего игрока для команды [1, 8 , 15].

Связующие игроки должны обладать точной передачей и пониманием игровой ситуации, быть сообразительными, иметь быструю реакцию и высокую подвижность, хорошее периферическое зрение, а также высокий уровень самоконтроля, выдержки и самообладания. Если учитывать деятельность связующего игрока, как регулятора взаимодействий команды, то количество значимых психофизиологических качеств значительно расширяется. Важным фактором успешности тактических действий в современном волейболе является антиципация. Именно здесь, как отмечает Е.Н. Сурков, данные процессы проявляются наиболее ярко [9].

Исследование проводилось на базе волейбольной команды глухих и слабослышащих спортсменов МБУ СП СШ «Аверс» г. Сургута.

Реализация поставленных задач исследование проводилась по следующим этапам:

1 этап - анализ состояния проблемы и выбор методики оценки эффективности игровых действий связующих игроков в волейболе.

2 этап - анализ игры связующих игроков в команде глухих волейболистов «Аверс» г. Сургута, и оценка эффективности их технико-тактических действий.

3 этап - разработка тренировочного модуля подготовки связующих игроков команды г. Сургута, с использованием поэтапного формирования навыков выбора решения на основе учета типичных игровых ситуаций.

4 этап - проверка эффективности тренировочного модуля подготовки связующих игроков команды г. Сургута, с использованием поэтапного формирования навыков выбора решения на основе учета типичных игровых ситуаций. Обсуждение результатов собственных исследований, формулирование выводов, составление практических рекомендаций.

На первом этапе исследования в ходе изучения литературных источников мы выявили следующую закономерность: все исследования и методические разработки, касающиеся тактики по большей части описывают командные тактические построения в атаке и защите. Они, как правило, содержат множество схем, описывающие игровые ситуации с фиксацией координат расположения игроков и их перемещений.

В то же время систематизация этого массива информации сопровождается рекомендациями по обучению и совершенствованию самого общего характера. Что касается индивидуальной тактической подготовки, в частности тактической подготовки связующих, то там наблюдается такая же ситуация. Исследования алгоритма принятия решения связующим игроком в научно-методической литературе фрагментарны и результаты этих исследований далеки от формы, пригодной для практического использования в учебно-тренировочном процессе $[1,4,8,11,13,15]$.

Мы полагаем, что этот факт является следствием описательной формы исследований, т.е. исследователи идут вслед за практиками, выполняя работы на фактическом материале существующих моделей игры и тренировки.

Большинство тренеров много времени тратят на техническую и физическую подготовку игроков при обучении. Кроме того, из-за большого количества занимающихся в группах, работа ведется фронтальным методом, в основном с использованием командных и групповых упражнений, и выделение отдельного времени на тренировку по принятию решений у связующего, для детских тренеров является часто трудной задачей. В волейболе глухих по причине сложной коммуникации эта проблема еще больше обостряется.

В принципе, в теории все компоненты для создания алгоритма принятия решения существуют, но поскольку от тренеров, работающих с резервом подобного заказа, не поступало, а квалифицированные команды решают эту проблему, используя собственные наработки в закрытом формате, то воз и ныне там.

Мы предприняли попытку собрать в технологическую цепочку принципы, средства и методы подготовки связующих в части оценки игровой обстановки и принятия решения в упрощенном виде, для того чтобы его можно было использовать в тренировке.

На основе интервьюирования тренеров были выделены следующие принципы, по которым связующий игрок выбирал решения тактической задачи:

А. Пасуй туда, куда удобно. Как правило, данным принципом пользуются новички, так как он является самым простым и удобным в использовании. В команде «Аверс» данным принципом связующий пользуется в тех случаях, когда ситуация считается сложной и применение других решений невозможно.

В. Дай передачу сильнейшему игроку. Подразумевается, что связующий игрок выполняет пас лидеру атак под лозунгом: «Умри, но забей», что гарантирует высокую результативность в большинстве ситуаций.

С. Переиграй блок противника, максимально облегчить задачу своим нападающим игрокам. 
D. Парадоксальные решения связующих игроков, чтобы соперник не смог рассчитать его действия.

Последние два принципа характерны для высококвалифицированных волейболистов и пользуются спросом в случае, когда прием мяча был выполнен точно.

Однако есть необходимость в понимании пользования данными принципами, а именно, на что ссылается связующий игрок, когда применяет один из них. Важно овладеть умением правильно оценить игровую ситуацию на волейбольной площадке во время игры.
По итогам интервьюирования квалифицированных тренеров Уральского федерального округа (4 заслуженных тренера России и 8 тренеров высшей категории) мы сделали вывод, что при формировании навыка принятия решения связующими игроками в основном используется метод целостного обучения. При этом часто игрок допускает ошибки в выборе направления, высоты и скорости передач для атаки, принимая решения спонтанно, без учета обстановки именно потому, что его не научили, каким принципом в какой ситуации пользоваться. Для более качественного и более динамичного обучения связующего игрока его тактическую подготовку предла-

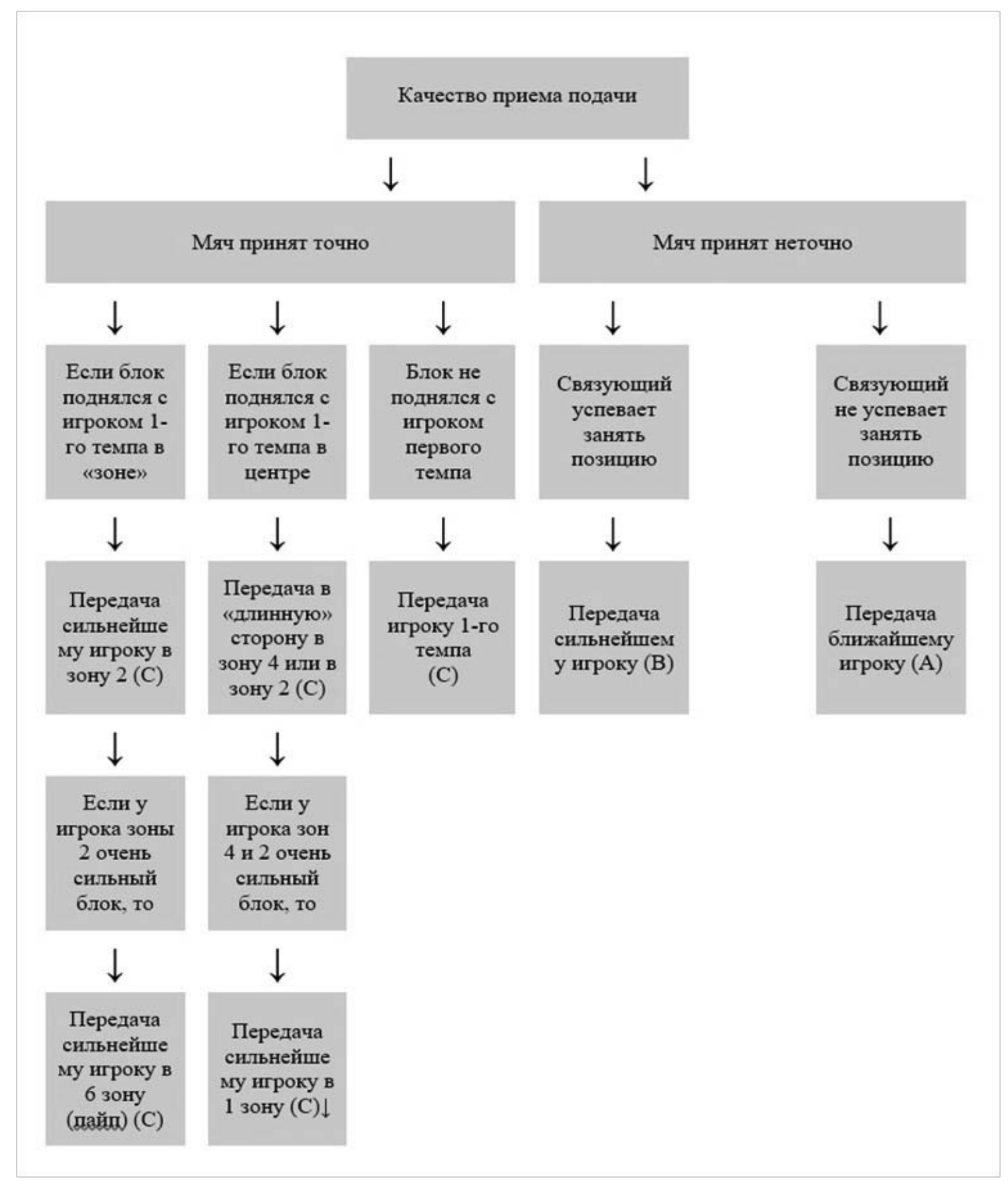

Рис. 1. Опорная модель тактических действий связующего «Дерево решений» 
гается выстроить на основе концепции поэтапного формирования умственных действий П.Я. Гальперина.

В результате наших теоретических изысканий, наблюдений и обсуждения с практиками была составлена опорная модель тактических действий связующего «дерево решений», где каждая точка бифуркации являлась этапом создания навыка выбора решения из двух, максимум трех альтернатив при выборе решения связующим игроком (Рис.1).

При анализе видеозаписи игры связующих мужской команды глухих волейболистов г. Сургута в финале чемпионата России 2020 года оценивалась правильность принятых решений в каждой ситуации экспертным методом. Три эксперта (два 3ТР и 1 ВК) большинством голосов ставили оценку, 1 балл - правильный выбор решения, 0 баллов - не правильный выбор.

Также рассчитывалась результативность, брак и эффективность атакующих действий в следующих ситуациях:

НП) мяч принят не точно, решение связующего (по мнению экспертов) правильное;

НН) мяч принят не точно, решение связующего не правильное;

ТП) мяч принят точно, решение связующего правильHoе;

ТН) мяч доведен, решение связующего не правильHoe.
Всего проанализировано 314 ситуаций (передач для атаки) в 5 партиях (Таблица 1).

В результате анализа данных эффективности игры связующего и показателей в атаке команды г. Сургута уровень тактической подготовки был оценен, как недостаточный (ниже среднего) и принято решение разработать тренировочный модуль тактической подготовки для связующих игроков.

На основе опорной модели тактических действий «дерево решений» (рис. 2) нами, совместно с тренерами МБУ СП СШ «Аверс» г. Сургута, был разработан тренировочный модуль тактической подготовки связующих в волейболе глухих.

Апробация тренировочного модуля подготовки связующих игроков проводилась в форме педагогического эксперимента в условиях учебно-тренировочного процесса команды глухих и слабослышащих волейболистов г. Сургута с октября 2020 года по апрель 2021 года (всего 6 месяцев). Для каждого этапа (блока) выполнялись упражнения по моделированию типичной игровой ситуации. В разделах 2, 3, 4 и 5 тренировочного модуля выполнялось от 2 до 8 тактических упражнений, всего 32 упражнения.

После того, как связующий игрок достигал порога необходимой и достаточной эффективности в принятии решений, он переходил к тренировке следующего этапа (Таблица 2).

Показатели эффективности игры связующих и показатели в атаке команды г. Сургута по результатам финальных игр ЧР 2020 года (n=314, \%)

\begin{tabular}{|l|c|c|c|c|}
\multicolumn{1}{|c|}{ Показатель } & HП & HН & \multicolumn{2}{c|}{$\begin{array}{c}\text { TП } \\
\%\end{array}$} \\
\hline Точность приема & $\%$ & \multicolumn{2}{c|}{$27,1 \pm 2,9$} \\
\hline Правильность выбора & \multicolumn{2}{|c|}{$36,2 \pm 3,1$} & $32,0 \pm 3,0$ & $68,1 \pm 3,5$ \\
\hline Результативность атаки & $38,4 \pm 4,2$ & $62,8 \pm 5,6$ & $52,5 \pm 3,9$ & $30,3 \pm 3,9$ \\
\hline Брак при атаке & $35,7 \pm 2,3$ & $20,2 \pm 3,4$ & $11,1 \pm 2,5$ & $16,2 \pm 4,0$ \\
\hline Эффективность атаки & $13,4 \pm 1,8$ & $17,0 \pm 4,1$ & $41,4 \pm 3,4$ & $14,1 \pm 3,9$ \\
\hline
\end{tabular}

Краткое содержание тренировочного модуля подготовки связующих игроков

Таблица 2.

\begin{tabular}{|l|l|}
\hline 1. & Теоретическая подготовка по изучению принципов выбора решения связующими игроками, на основе опорной модели «Дерево решений» \\
\hline 2. & Блок упражнений по оценке связующим ситуаций «мяч принят точно - неточно», «успеваю занять позицию для передачи - не успеваю». \\
\hline 3. & $\begin{array}{l}\text { Блок упражнений по отработке ситуаций при неточном приеме «передача адресуется сильнейшему игроку», «передача адресуется ближайшему } \\
\text { игроку». }\end{array}$ \\
\hline 4. & Блок упражнений по отработке ситуаций при точном приеме «передача первому темпу на опережение», «передача второму темпу на разрыв блока» \\
\hline 5. & Моделирование игровых ситуаций при чередовании точного и не точного приема \\
\hline 6. & Совершенствование выбора решений в игровых условиях \\
\hline
\end{tabular}


Показатели эффективности игры связующих и показатели в атаке команды г. Сургута по результатам финальных игр ЧР 2021 года (n=367, \%)

\begin{tabular}{|c|c|c|c|c|}
\hline Показатель & $\begin{array}{c}\mathrm{HП} \\
\%\end{array}$ & $\begin{array}{l}\mathrm{HH} \\
\%\end{array}$ & $\begin{array}{l}\text { ТП } \\
\%\end{array}$ & $\begin{array}{l}\text { TH } \\
\%\end{array}$ \\
\hline Точность приема & \multicolumn{2}{|c|}{$34,6 \pm 4,7$} & \multicolumn{2}{|c|}{$22,5 \pm 3,9$} \\
\hline Правильность выбора & $56,2 \pm 4,0$ & $43,8 \pm 4,6$ & $51,7 \pm 4,2$ & $48,3 \pm 3,2$ \\
\hline Результативность атаки & $40,5 \pm 2,7$ & $20,3 \pm 3,2$ & $66,4 \pm 5,9$ & $30,0 \pm 3,7$ \\
\hline Брак при атаке & $10,1 \pm 1,2$ & $16,2 \pm 4,0$ & $10,2 \pm 2,3$ & $15,8 \pm 3,4$ \\
\hline Эффективность атаки & $30,4 \pm 2,4$ & $4,1 \pm 3,5$ & $56,2 \pm 4,0$ & $14,2 \pm 3,6$ \\
\hline
\end{tabular}

Динамика показателей эффективности игры связующих команды

Таблица 4. г. Сургута в результате педагогического формирующего эксперимента

\begin{tabular}{|l|c|c|c|c|}
\multicolumn{1}{c|}{ Показатель } & HП & HН & ТП & TH \\
$\%$ & $\%$ & $-19,8 \pm 2,9^{*}$ \\
\hline Правильность выбора & $17,8 \pm 2,2^{*}$ & $-17,8 \pm 2,2^{*}$ & $19,8 \pm 2,9^{*}$ & $0,3 \pm 0,0$ \\
\hline Результативность атаки & $4,8 \pm 0,9^{*}$ & $-0,1 \pm 0,0$ & $13,9 \pm 2,9^{*}$ & $-0,4 \pm 0,0$ \\
\hline Брак при атаке & $-3,3 \pm 0,1$ & $0,8 \pm 0,1$ & $-0,9 \pm 0,1$ & $0,7 \pm 0,1$ \\
\hline Эффективность атаки & $8,1 \pm 1,1^{*}$ & $0,9 \pm 0,1$ & $14,8 \pm 3,0^{*}$ & \\
\hline
\end{tabular}

* - различия показателей до и после эксперимента достоверны при $p \leq 0,05$

В апреле 2021 года мы рассчитали эффективность игры связующего и показателей в атаке команды г. Сургута в финальной игре ЧР 2021 года по волейболу среди глухих и слабослышащих (Таблица 3). Всего проанализировано 367 ситуаций (передач для атаки) в 5 партиях.

Эффективность тренировочного модуля оценивалась по динамике показателей эффективности игры связующего команды г. Сургута в результате педагогического формирующего эксперимента (Таблица 4).

За время эксперимента достоверно повысилась правильность выбора решений связующих при неточном приеме (соответственно уменьшился процент неправильных решений) - на 17,8\%, а при точном приеме на $19,8 \%$.

При этом результативность атаки (средние показатели по команде) достоверно повысились при выборе правильного решения связующим после неточного приема на 4,8\% и после точного приема на $13,9 \%$.

Эффективность показателей атаки (результативность минус брак) достоверно повысились при выборе правильного решения связующим после неточного приема на $8,1 \%$ и после точного приема на $14,8 \%$.

При неправильном выборе решений связующими результативность и эффективность атаки у команды за время эксперимента не изменились, что подтверждает роль связующего в повышении уровня командных показателей атакующих действий.

\section{Выво $\Delta ы$}

1. Изучение данных научно-методической литературы и показатели игровых действий команд по статистической документации свидетельствует, что проблема научного обоснованного совершенствования тактического мастерства связующих игроков в волейболе глухих существует и требует дальнейшего разрешения. Сформулированы методические основания и выявлены принципы, по которым связующий выбирает решение тактической задачи, что позволяет создать модель тренировочного процесса с целью улучшения тактических действий связующих игроков.

2. Проведен анализ игры связующих игроков в команде глухих волейболистов г. Сургута, и дана оценка эффективности их тактических действий.

3. Разработан тренировочный модуль тактической подготовки связующих игроков команды г. Сургута, с использованием поэтапного формирования навыков выбора решения на основе учета типичных игровых ситуаций.

4. Экспериментально проверена и доказана эффективность тренировочного модуля тактической подготовки связующих игроков команды глухих и слабослышащих волейболистов г. Сургута, с использованием поэтапного формирования навыков выбора решения на основе учета типичных игровых ситуаций.

Результаты проведенного исследования подтвердили выдвинутую нами гипотезу. 


\section{ЛИТЕРАТУРА}

1. Астахов Е.Г. с соавт. Формирование тактической подготовленности юных волейболистов к выполнению вторых передач мяча / Е.Г. Астахов, А.А. Гераськин, И.Ф. Андрущинин. - Конференция: «Физическая культура и спорт в жизни студенческой молодежи». - 0мск, 2015. - С. 7.

2. Беляев А.В. Волейбол: теория и методика тренировки: Учебное пособие / А.В. Беляев, Л.В. Булыкина. - М.: ТВТ Дивизион, 2011. - 184 с.

3. Железняк Ю.Д. Программа для спортивных школ. - М.: Спорткомитет РФ, 2002. - 48 с.

4. Ивойлов А.В. Тактическая подготовка волейболистов. - Минск, 2000. - 111 с.

5. Луктова Н.В. с соавт. Способы оценки эффективности соревновательной деятельности в волейболе: Учебно-методическое пособие / Н.В. Луткова, Н.В. Дашкевич. - Санкт-Петербург, 2008. - 48 с.

6. Марков К.К. Инновационные направления совершенствования технологий спортивной тренировки. - Иркутск, ИрНИТУ, $2016 .-187$ с.

7. Праведников В.М. Пути повышения технико-тактического мастерства связующего / В.М. Праведников, Э.А. Морозова. - Журнал: «Актуальные проблемы развития физической культуры и спорта в современных условиях. 2016, - №1. - С.179-185.

8. Слупский Л.Н. Волейбол: игра связующего. - М. : Физкультура и спорт, 1984. - 96 с.

9. Сурков Е.Н. Антиципация в спорте. - М. : Физкультура и спорт, 1982. - 144 с.

10. Федеральный стандарт спортивной подготовки по виду спорта волейбол - М.: Спорт, 2016. - 24 с. [Электронный ресурс] Режим доступа: http://www.iprbookshop.ru/65586.html.

11. Фомин Е.В. Технико-тактическая подготовка волейболистов: методическое пособие / Е.В. Фомин, Л.В. Булыкина, А.В. Суханов. - М., 2014. - 56 с.

12. Шипулин Г.М. Эффективность технико-тактических действий в соревновательной деятельности высококвалифицированных волейболистов / Г.М. Шипулин, 0.Э. Сердюков. - Журнал «Теория и практика физической культуры» 2002. - №1. - С. 37-38.

13. Шулятьев В.М. Содержание и организация тренировочного процесса волейболистов: Методические рекомендации. - 0мск: 0мПИ, 1990. - 24 с

14. Шулятьев В.М. Теоретико-методические и организационные основы подготовки резервов квалифицированных волейболистов. - М., 1997, С. $125-263$.

15. Эртман Ю.Н. с соавт. Совершенствование технико-тактической подготовки связующих игроков при выполнении второй передачи в волейболе. / ЮН. Эртман, ЕЮ. Ковыршина, А.А. Кондрашова, Д.В. Ходус. - Журнал «Ученые записи университета ИМ. П.Ф. Лесгафта» 2020. - № 4. - С. $531-534$.

( Ш Шнейдер Виктор Юдович (shv.53@mail.ru).

Журнал «Современная наука: актуальные проблемы теории и практики»

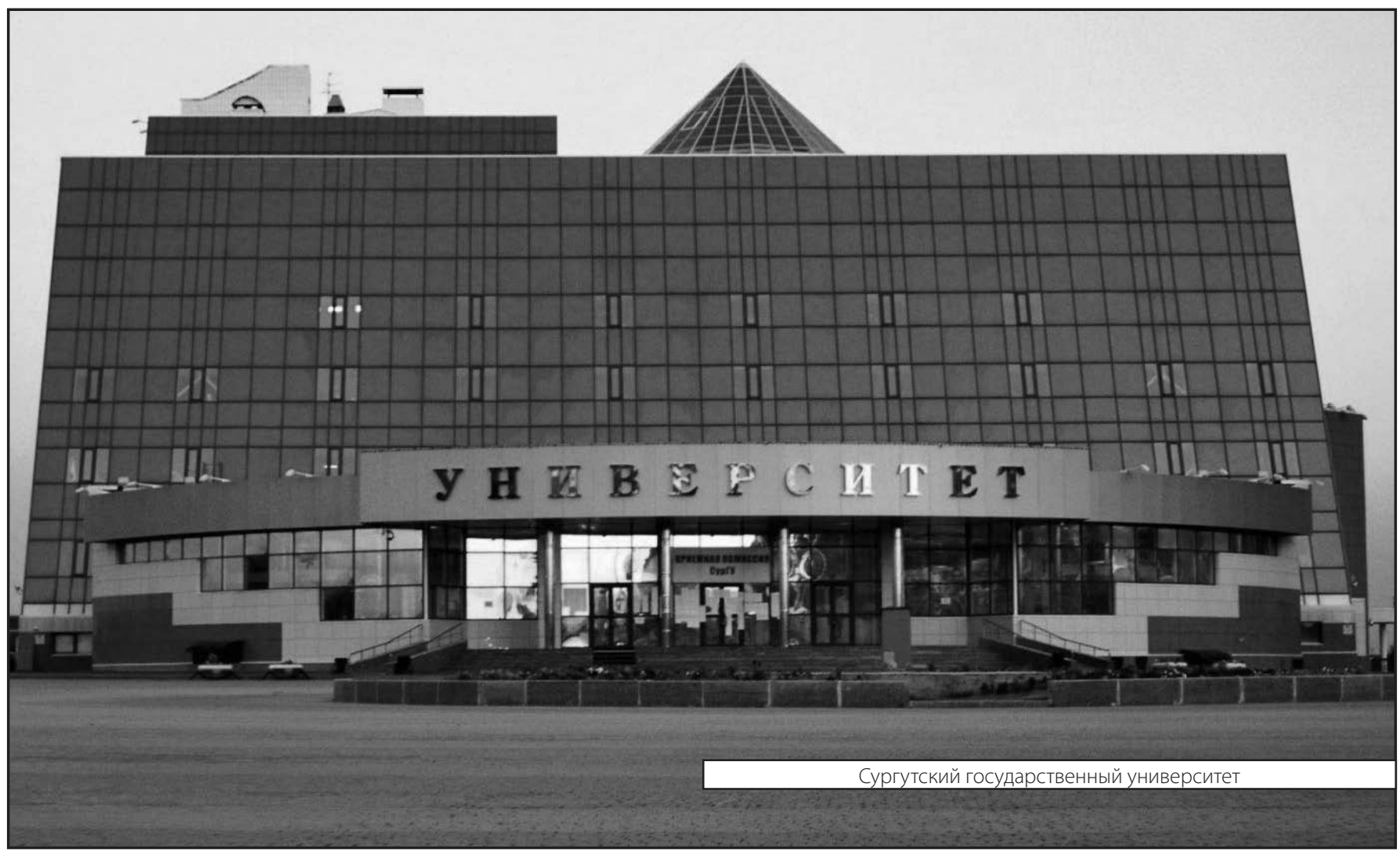

